\title{
VISUAL JO2: Um Objeto de Aprendizagem para o Ensino de Programação Java a Deficientes Físicos e Auditivos através do Estímulo Visual - Um Estudo de Caso
}

\author{
Maikon Igor da Silva Soares - IFCE - maikonigor@gmail.com \\ Corneli Gomes Furtado Júnior - IFCE - cjunior@ifce.edu.br \\ Lidiane Castro Silva - UECE - lidcastro@gmail.com \\ Francisco Carlos de Mattos Brito de Oliveira - UECE - fran.mb.oliveira@gmail.com \\ Rafael Bezerra de Oliveira - IFCE - rafaelbezerra195@gmail.com \\ Nelson Alex Silva Lima - UECE - nelson182alex@gmail.com \\ Éder Furtado Soares - Dell Computadores - eder_soares@dell.com
}

\begin{abstract}
RESUMO
Neste trabalho apresentamos o Visual JO2, um objeto de aprendizagem acessível, que tem por objetivo o ensino de linguagem de programação Java a pessoas com deficiência física e auditiva através do estímulo visual. O Visual JO2 foi aplicado a quatro equipes de testes com doze membros cada, todos portadores de deficiência, tratados como alunos de um curso piloto, e os resultados apresentados neste trabalho. A metodologia de testes utilizada permite a construção de um conteúdo educacional de qualidade, adequado às necessidades de um público bastante exigente.
\end{abstract}

Palavras-Chave: Objeto de Aprendizagem, Java, Acessibilidade

\section{Visual JO2: A Java Learning Object for People With Physical and Hearing Disabilities Through Visual Stimulus - A Case Study}

\begin{abstract}
In this paper we introduce Visual JO2, an accessible learning object focused on visualoriented programming language teaching process, for people with physical and hearing impairment. The results shown in this paper were produced by the use of Visual JO2 in four test teams, each composed by 12 people with disabilities, working in a student-like placement. The chosen methodology provides a track for good quality content production, suitable for the special needs of people with physical and hearing impairments.
\end{abstract}

Key words: Learning object, Java, Accessibility

\section{INTRODUÇÃO}

O Brasil possui cerca de 45 milhões de pessoas com deficiência (PCD) (IBGE, 2014), uma parcela significativa da população que enfrenta problemas para acessar recursos tecnológicos a favor da formação profissional. Em contrapartida, temos um mercado de trabalho promissor em que fica evidente a falta de profissionais qualificados para preencher as mais diversas vagas. É necessário, portanto, oferecer soluções tecnológicas capazes de qualificar um grande número de PCD, explorando de maneira adequada suas habilidades e contornando suas deficiências, atendendo, assim, as necessidades de acessibilidade deste público.

O laboratório Le@d, criado a partir de investimentos da empresa Dell Computadores, pesquisa e desenvolve tecnologias e conteúdo de educação à distância $(\mathrm{EaD})$ aplicados à formação de pessoas com deficiência física e pessoas com deficiência auditiva. Todos os materiais e ferramentas construídos são validados e testados por quatro equipes de testadores de software, todos PCD física e auditiva. Dessa forma, os artefatos criados são aprimorados com o foco no usuário final, para que o aluno receba um material de qualidade, adaptado às suas necessidades de 
aprendizagem (Furtado, 2014).

Este trabalho apresenta o Visual JO2 (Visual Java Object Oriented), um Objeto de Aprendizagem (OA) construído sob critérios de acessibilidade para o ensino de programação à PCD. Introduzimos ainda o ensino de linguagem de programação orientada ao visual. Através desse paradigma objetiva-se facilitar o aprendizado através do estímulo da visão.

Este documento é organizado da seguinte maneira: após a introdução, realizada nessa seção, os trabalhos relacionados são apresentados na seção 2; a seção 3 aborda as características gerais de um Objeto de Aprendizagem e uma descrição sobre o conteúdo produzido pelo Le@d. Uma abordagem ao paradigma de programação orientada ao visual é descrito na seção 4. A seção seguinte descreve a metodologia de testes e os resultados obtidos pela aplicação do OA à equipe de testes. Por fim, as considerações finais na seção 6 .

\section{TRABALHOS RELACIONADOS}

A denominação Objeto de Aprendizagem (OA) é largamente empregada e difundida para denominar conteúdos digitais aplicados em educação. Um OA pode ser compreendido como qualquer entidade, digital ou não, que pode ser usada, reutilizada ou referenciada durante o processo de aprendizagem provido por algum tipo de tecnologia (IEEE, 2010), útil ao ensino ou aprendizagem. Outros significados de OA ampliam ou limitam sua definição e alguns sugerem que ele deve ser interativo (Múzio, 2001).

O Sistema Imersivo para Pessoas com Deficiência (SIPD) (Piovesan, 2013) é um software que utiliza realidade virtual para criação de um ambiente imersivo no qual o usuário tem a sensação de estar inserido em um mundo paralelo. O SIPD atua de forma multissensorial, explorando os sentidos de visão, audição e tato, e tem por objetivo a qualificação de PCD e sua inclusão no mercado de trabalho. A partir da construção e imersão dos PCD em um ambiente de trabalho virtual, semelhante ao que o este encontrará na vida real, espera-se que o aluno com deficiência conheça e pratique previamente as atividades relacionadas à sua ocupação. Esse processo, além de formação profissional, proporciona mais segurança aos PCD à realização de tarefas cotidianas.

Piccolo (Piccolo, 2010) propôs um ambiente interativo e adaptável para o ensino de linguagem de programação Pascal, denominado TutorICC. Este é utilizado em cursos semipresenciais da Universidade de Brasília para apoiar, entre outras coisas, a realização de práticas de laboratório e aplicação de avaliações. A apresentação dos conteúdos é feita através de níveis de dificuldade, permitindo ao aluno a escolha do caminho mais conveniente para ele dentro do conteúdo apresentado na disciplina. O TutorICC provê interatividade, convidando o aluno a construir seus programas passo-a-passo seguindo um tutorial. Os programas construídos são corrigidos automaticamente pela ferramenta, que recomenda ao aluno, caso necessário, que reforce conceitos apresentados em assuntos anteriores.

O Blind Education and Mathematics (BEM) (Dantas, 2013) é um OA construído sob a forma de um jogo eletrônico, cujo objetivo é a disponibilização de um recurso educacional alternativo para auxiliar na formação de crianças deficientes visuais ou não. A sistemática para a construção do BEM é composta por três etapas: levantamento de requisitos, desenvolvimento e, por fim, a aplicação e evolução do OA. A primeira fase busca entender o universo da criança, deficiente visual ou não, para construção de um conteúdo educacional específico para este público. A etapa seguinte trata da codificação do OA propriamente dito. Por fim, a última fase busca a evolução do BEM a partir de sua aplicação e feedback do público infantil. Dantas (Dantas, 2013) reconhece o BEM como uma ferramenta que trabalha o caráter motivacional da criança, facilitando o aprendizado das quatro operações fundamentais da matemática.

O trabalho de Blatto-Vale (Blatto-Valle et al, 2007) aponta que a representação visual de problemas matemáticos é um ponto crucial, e muitas vezes decisivo, para a solução destes problemas por alunos surdos. Para Pinto (Pinto et al, 2014), o uso da visualidade representa para o 
surdo o principal canal de pensamento e processamento de esquemas que naturalmente permitem a aquisição, construção e expressão de conhecimentos, valores e experiências, e que sem isso estes seriam incomunicáveis.

Neste trabalho apresentamos o Visual JO2, um objeto de aprendizagem que faz uso do sentido da visão para estimular o cognitivo de alunos com deficiência física ou auditiva. Embora a Programação Orientada ao Visual (POV) seja uma área de pesquisa que data dos anos setenta, os trabalhos relacionados encontrados (Barbosa, 2009) e (Farinelli, 2007) fazem a representação visual de um objeto através de um diagrama de classes. O Visual JO2, diferente dos demais, descreve um objeto como uma estrutura física concreta da entidade que se quer representar. Assim, um objeto pertencente à classe "SerHumano", que contém os atributos “corDaPele”, “calca”, "camisa”, "sapatos”, “olhos”, “cabelo” e "nome” definidos com parâmetros branca, azul, vermelha, preto, azuis, preto e Pedro, respectivamente, serão apresentados segundo a Figura 1 (B), ao invés de seguirem a representação da classe da Figura 1 (A).

\begin{tabular}{|l|}
\hline \multicolumn{1}{|c|}{ SerHumano } \\
\hline - corDaPele : String \\
- calca : String \\
- camisa : String \\
- sapato : String \\
- olhos : String \\
- cabelo : String \\
- nome : String \\
\hline+ andar() : void \\
+ pular() : void \\
+ sentar() : void \\
+ levantar() : void \\
+ oi() : void \\
+ obrigado() : void
\end{tabular}

Figura 1 (A) - Representação da classe "SerHumano"

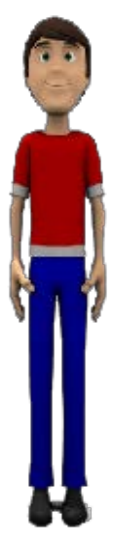

Figura 1 (B) - Representação da classe "Ser Humano" adotada pelo Visual JO2

Na seção seguinte apresentamos o Visual JO2 e os recursos de acessibilidade que este disponibiliza, além de demostrarmos como o estímulo da visão pode facilitar o aprendizado de linguagem de programação.

\section{VISUAL JO2: ÁREAS FUNCIONAIS E RECURSOS DISPONÍVEIS}

O Visual JO2 é disponibilizado à equipe de testes por intermédio do ead2pcd, Ambiente Virtual de Aprendizagem (AVA) desenvolvido e adotado pelo Le@d. Cada membro da equipe de testes, cadastrados no AVA com o perfil de estudante, contém um atributo que define sua deficiência: auditiva, física ou ambas. O uso desse atributo permite que o sistema identifique a deficiência do aluno e o ofereça uma versão do Visual JO2 compatível com suas limitações

A Figura 2 apresenta uma versão do Visual JO2 para PCD (A) surdos e (B) físicos. Embora exista a exibição diferenciada a alunos com diferentes perfis de deficiência, todos os recursos de acessibilidade estão disponíveis para ambos os perfis.

Isso permite, por exemplo, que um PCD físico faça uso do Visual JO2 com o recurso de tradução para Língua Brasileira de Sinais (Libras).

Os conteúdos e recursos do Visual JO2 estão distribuídos em quatro Áreas Funcionais (AF): AF Conteúdo Didático e Exercícios, AF Tradução e Navegação por Tópico, AF Acessibilidade e AF Instruções e Navegação por Slide. Nas subseções seguintes apresentaremos os detalhes de cada AF. 


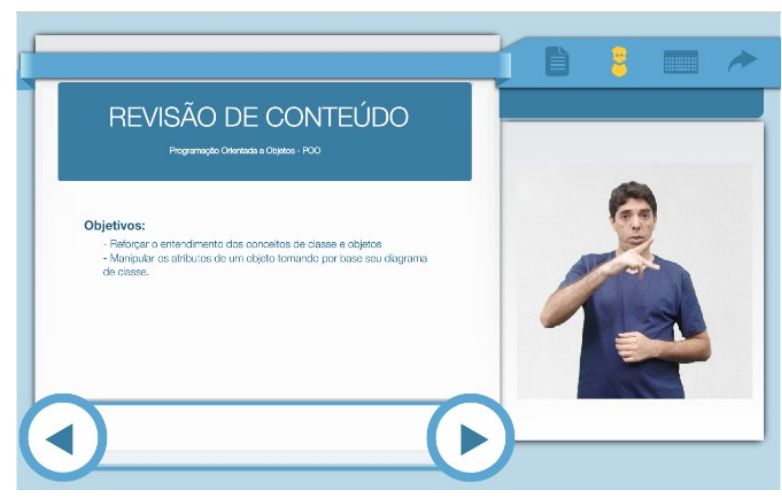

Figura 2 (A) - Visualização do Visual JO2 para PCD Surdo

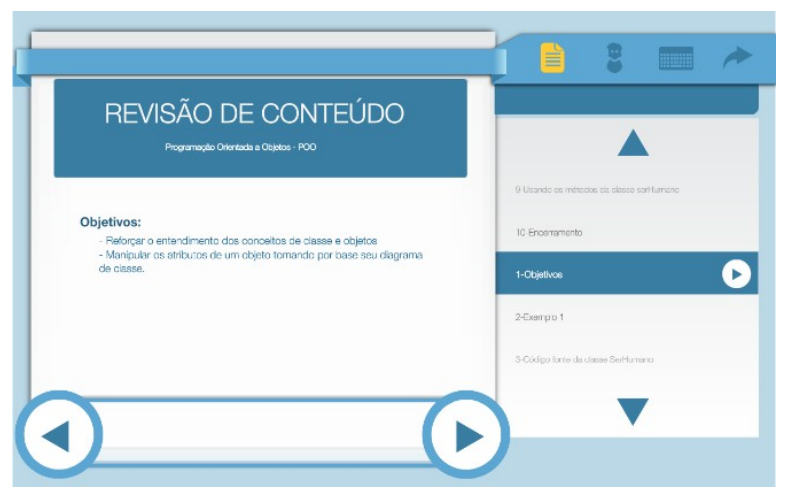

Figura 2 (B) - Visualização do Visual JO2 para PCD Físico

\subsection{AF Conteúdos Didáticos e Exercícios}

O Visual JO2 disponibiliza ao aluno uma leitura, proposta por um professor conteudista (PC) especialista na área de programação de computadores, relacionada ao assunto abordado na aula. Essa leitura, rica em exemplos, deve ser capaz de transmitir ao aluno, de forma suave e amigável, todo o embasamento teórico necessário sobre o conteúdo estudado.

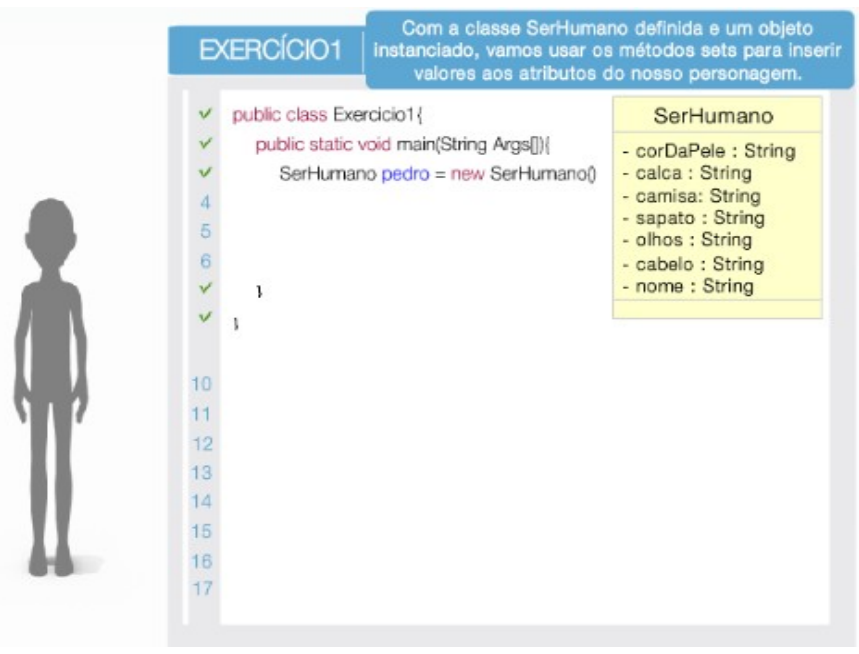

Figura 3 - AD Incorporado ao Visual

JO2.

Ao final de cada tópico, ou a critério do PC, são propostos exercícios práticos para a fixação do assunto abordado. Esses exercícios devem ser realizados diretamente no Ambiente de Desenvolvimento (AD) incorporado ao Visual JO2, apresentado através da Figura 3. Este ambiente, entre outras coisas, é responsável por receber o código referente à resposta de um exercício, validálo, indicar possíveis erros e exibir ao aluno uma imagem com os atributos do objeto instanciado.

\subsection{AF Tradução e Navegação por Tópicos}

A “AF Tradução e Navegação por Tópicos”, responsável por disponibilizar o conteúdo didático através de Libras e um menu de navegação rápida por todos os tópicos que compõem uma aula pode assumir três configurações de visualização. São elas: intérprete, tópicos de aula e tópicos de aula e intérprete.

A primeira opção de visualização, apresentada através da Figura 2 (A), oferta ao aluno o conteúdo da AF “Conteúdos Didáticos e Exercícios” através de Libras. Nessa opção de visualização assume-se que o aluno é PCD auditivo. Na segunda opção de visualização, apresentada pela Figura 2 (B), a tradução dá lugar a uma lista de tópicos de navegação. Acessando esses tópicos, o aluno é capaz de mover-se diretamente a assuntos específicos dentro de uma aula. Nesta 
configuração,assume-se que o aluno é PCD físico, portanto não necessita da visualização do interprete. Por fim, a terceira opção de visualização, apresentada pela Figura 4, fornece ao aluno, considerado PCD auditivo, a visualização e tradução do menu de navegação por tópicos de uma aula.

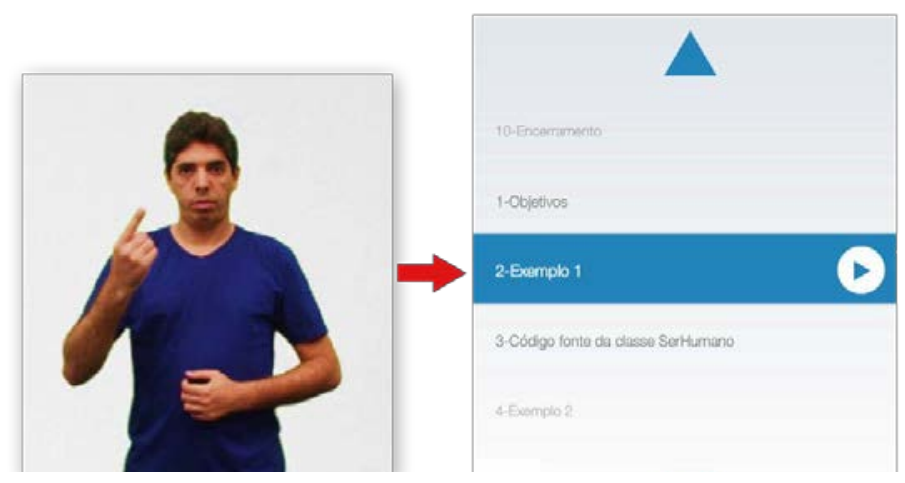

Figura 4 - Apresentação dos Tópicos de Aula e Intérprete.

\subsection{AF Acessibilidade}

O menu acessibilidade, disponível através da "AF Acessibilidade”, contém os recursos que ajudam ao PCD no contorno de suas deficiências. É a partir desta AF que os alunos escolhem por uma das três opções de visualização apresentadas na subseção anterior.

O teclado virtual, apresentado através da Figura 5, é outro recurso de acessibilidade incorporado ao Visual JO2. Através deste, os alunos podem, com apenas um dedo ou com auxílio de outros instrumentos físicos (muitas vezes criados ou sugeridos por profissionais de terapia ocupacional), navegar e realizar todas as atividades de uma aula.

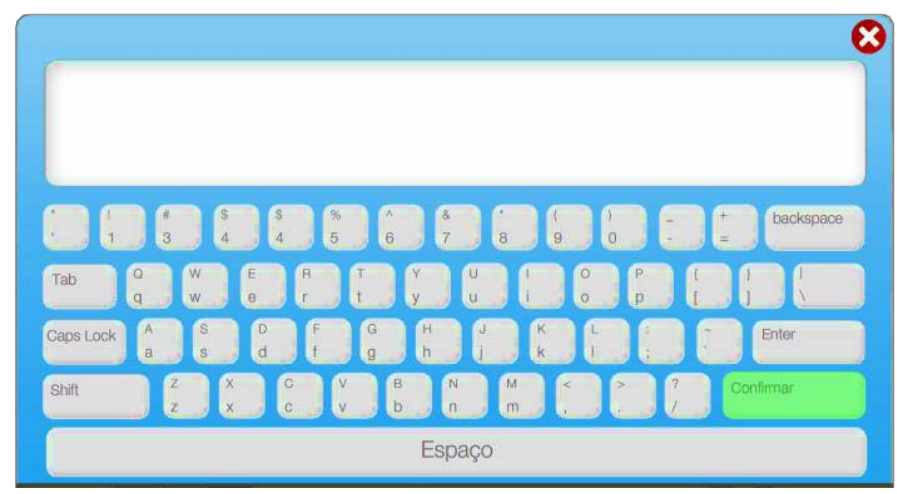

Figura 5 - Teclado Virtual.

\subsection{AF Instruções e Navegação por Slide}

A “AF Instruções e Navegação por Slide”, apresentada através da Figura 6, fornece ao aluno informações importantes, dicas ou pequenas informações adicionais que foram previstas pelo PC no momento da concepção da aula.

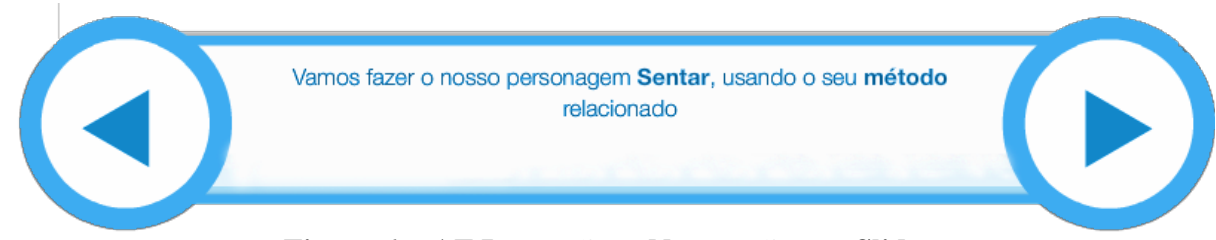

Figura 6 - AF Instruções e Navegação por Slide. 
Os botões no formato de setas para direta e esquerda permitem ao aluno navegar tela a tela dentro de um tópico de aula.

Na seção seguinte apresentaremos o estímulo visual de que trata o Visual JO2.

\section{VISUAL JO2 E O ENSINO DE PROGRAMAÇÃO ATRAVÉS DO ESTÍMULO VISUAL}

Em Programação Orientada a Objetos (POO) um objeto é uma abstração para algo do mundo real. Por exemplo, um ser-humano possui algumas características e comportamentos que permite percebê-lo, como cor da pele, cor dos olhos, cor dos cabelos, estatura, modo de andar, modo de sentar, dentre outros. Essas características e comportamentos podem ser abstraídos em uma classe. O Visual JO2 trata um objeto não como uma abstração de um elemento da vida real, mas como algo concreto, palpável. Assim, o aluno pode construir seus próprios objetos, manipulá-los e visualizar o resultado de sua criação.

Um exemplo dessa concretização do abstrato pode ser observado através de uma atividade proposta no Visual JO2. O exercício inicia apresentando uma classe de objetos e pede ao aluno que instancie um objeto pertencente a esta classe e faça uso dos métodos disponíveis para construir e manipular o objeto.

A Figura 7 (A à F) apresenta todas as etapas de representação de um objeto, desde a instanciação (Figura 8A) até sua completa representação (Figura 7F). No momento em que há a instanciação de um objeto, que pode ser realizada através da instrução SerHumano Pedro = new SerHumano(); a representação concreta deste objeto (desde que possível) é apresentada ao aluno (Figura 7 A). As Figuras 7 (B), $7(C), 7$ (D) e 7 (E) apresentam quatro etapas intermediárias do exercício. Observa-se que na Figura 7 (F) o objeto Pedro está com todos os atributos definidos. Para isso foram utilizados os métodos get $^{1}$ e set $^{2}$ da classe SerHumano.

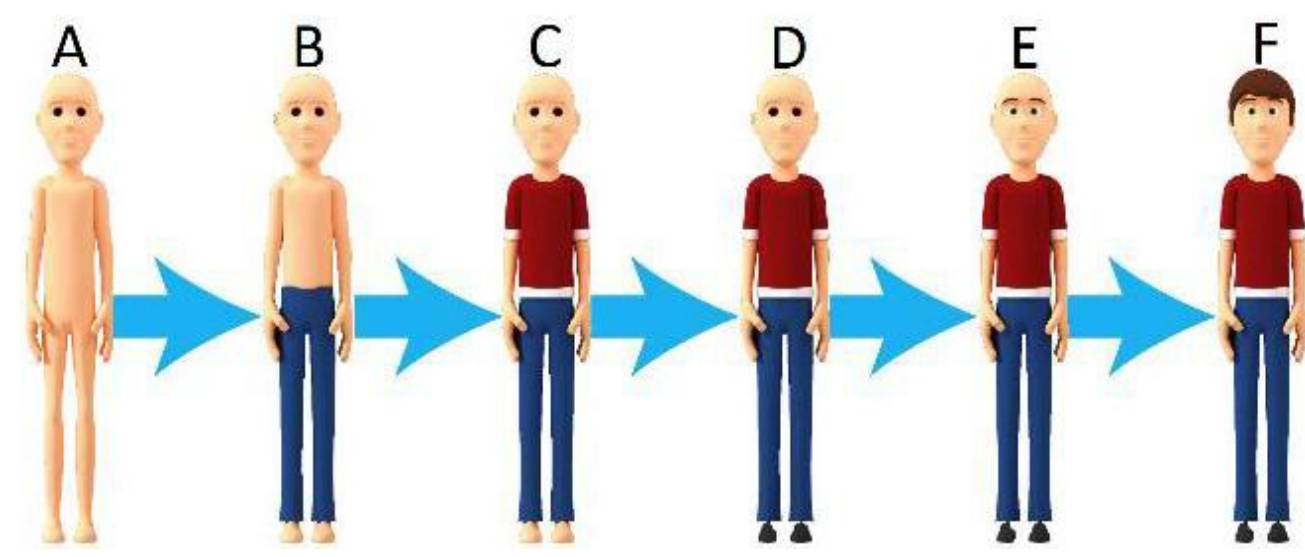

Figura 7 - Etapas da instanciação de um Objeto no Visual JO2.

A próxima etapa da atividade, que acontece após o aluno definir todas as características do objeto, pede para que este faça uso dos métodos andar (), pular () e sentar () disponíveis na classe "SerHumano" para modificar o comportamento do objeto Pedro. Os resultados da aplicação desses métodos podem ser visualizados através das Figuras 8(A), 8(B) e 8(C), respectivamente.

\footnotetext{
1 Método padrão utilizado para recuperar atributos de um objeto.

2 Método padrão utilizado para definer atributos de um objeto.
} 


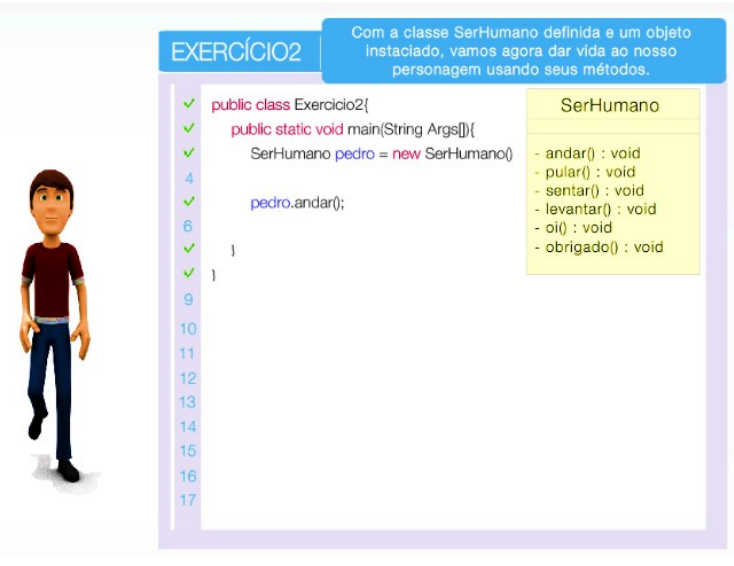

Figura 8(A) - Execução do método andar()

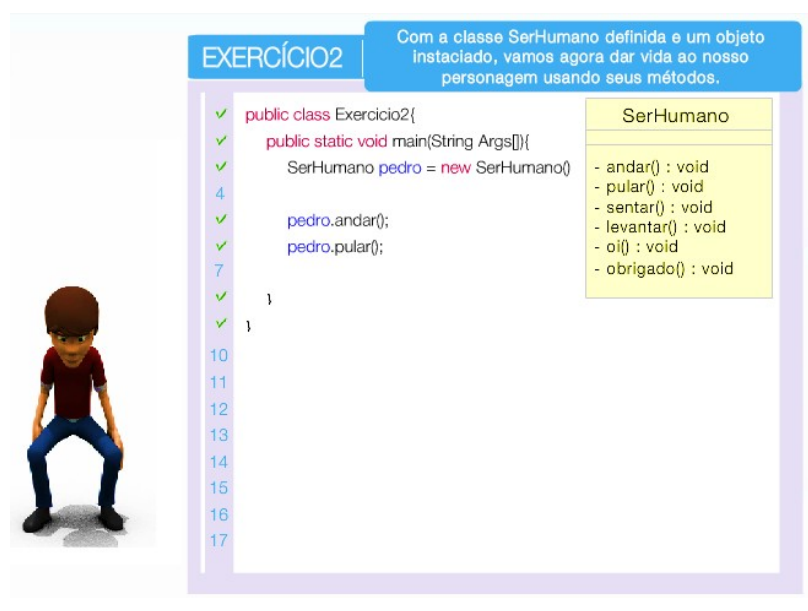

Figura 8(B) - Execução do método pular()

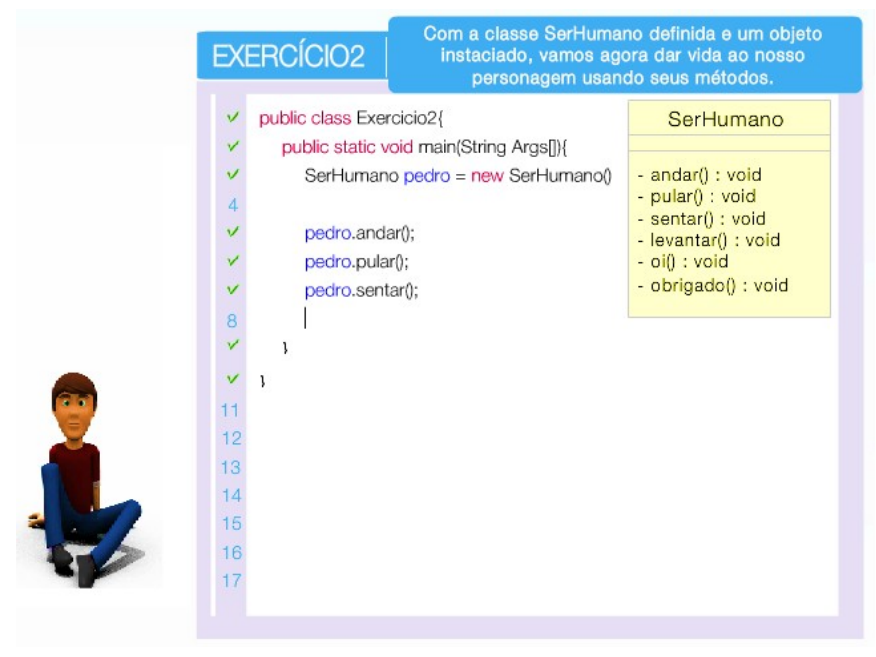

Figura 8 (C) - Execução do método sentar ().

Assim, concretizando o abstrato e fazendo uso de fortes interações com o aluno, o Visual JO2 busca o incentivo ao ensino-aprendizado de linguagem de programação Java, daí a origem de seu nome Java Object Oriented.

\section{VISUAL JO2: METODOLOGIA DE TESTES E EVOLUÇÃO DOS OA DO LE@D}

Furtado (Furtado, 2014) apresenta através de Redes de Petri Coloridas (RPC) o modelo de construção e validação dos OA desenvolvidos pelo Le@d. Entretanto, por questões de limitação de espaço foram detalhadas apenas duas etapas intermediárias de produção desses conteúdos. Nesta seção detalhamos a etapa de testes e evolução na qual está inserido o Visual JO2.

Cada OA construído pelo Le@d é submetido a três das quatro equipes de testes disponíveis, contendo doze membros cada, todos PCD física, auditiva ou ambas. Após a aplicação desse conteúdo à equipe de testes, tratados como alunos de um curso piloto, são coletadas críticas, sugestões, indicativos de erros no sistema e pareceres de acessibilidade sobre o conteúdo produzido.

Essas informações são elencadas, categorizadas como melhorias ou conserto (bugs) e enviadas à equipe de desenvolvimento, composta por professores, pedagogos, revisores ortográficos, ilustradores, animadores, programadores, dentre outros, para que estes possam decidir sobre a 
incorporação ou não da melhoria. Erros são automaticamente encaminhados à equipe de programação para serem consertados.

Após a evolução dos OA, uma nova rodada de aplicação do material é realizada com a quarta equipe de teste. Novamente são coletadas críticas, sugestões, indicativos de erros no sistema e pareceres de acessibilidade sobre o conteúdo produzido, e a evolução do material é decidida pela equipe de desenvolvimento. Dessa forma, com dois ciclos de testes e evolução, pretende-se eliminar todos os possíveis erros associados ao conteúdo e contemplar o maior número de sugestões de melhoria elencados pela comunidade PCD. Objetiva-se, portanto, a construção de um conteúdo com qualidade para atender a um público bastante exigente. A seção seguinte apresenta os resultados obtidos pela aplicação do Visual JO2 e Aplicação da Metodologia de testes adotada pelo Le@d.

\subsection{RESULTADOS OBTIDOS}

As aulas produzidas pelo Le@d, disponíveis através do AVA ead2pcd, são compostas por três tipos de conteúdos digitais: web aulas, vídeo aulas e OA.

Uma pesquisa realizada entre os quarenta e oito PCD das equipes de testes mostra que cem por cento destes utilizam o Visual JO2 como primeiro recurso didático na busca do conhecimento prático e teórico. A Tabela 1 apresenta de forma resumida o percentual de PCD e o motivo que o fez adotar o JO2 visual como primeira opção na busca do conhecimento prático e teórico.

Tabela 1 - Resultados da pesquisa com a equipe de testes.

\begin{tabular}{c|c|c} 
Percentual & $\mathbf{N}^{\circ}$ de PCD & Motivo da adoção da Ferramenta \\
\hline $67 \%$ & 32 & Atraídos pelo Visual \\
\hline $30 \%$ & 14 & Atraídos pelo caráter prático \\
\hline $3 \%$ & 2 & Atraídos pela Interatividade
\end{tabular}

Do total, sessenta e sete por cento afirmam que são atraídos pela forma como é realizada a apresentação do conteúdo na ferramenta. Trinta por cento adotam o Visual JO2 pelo caráter prático. O restante do grupo diz ser atraído pela interatividade promovida pela ferramenta.

Em relação à metodologia de testes e evolução dos OA desenvolvidos no Le@d, o gráfico da Figura 9 apresenta o número de erros e sugestões de melhorias para um total de dez aulas produzidas que serão apresentadas através do Visual JO2.

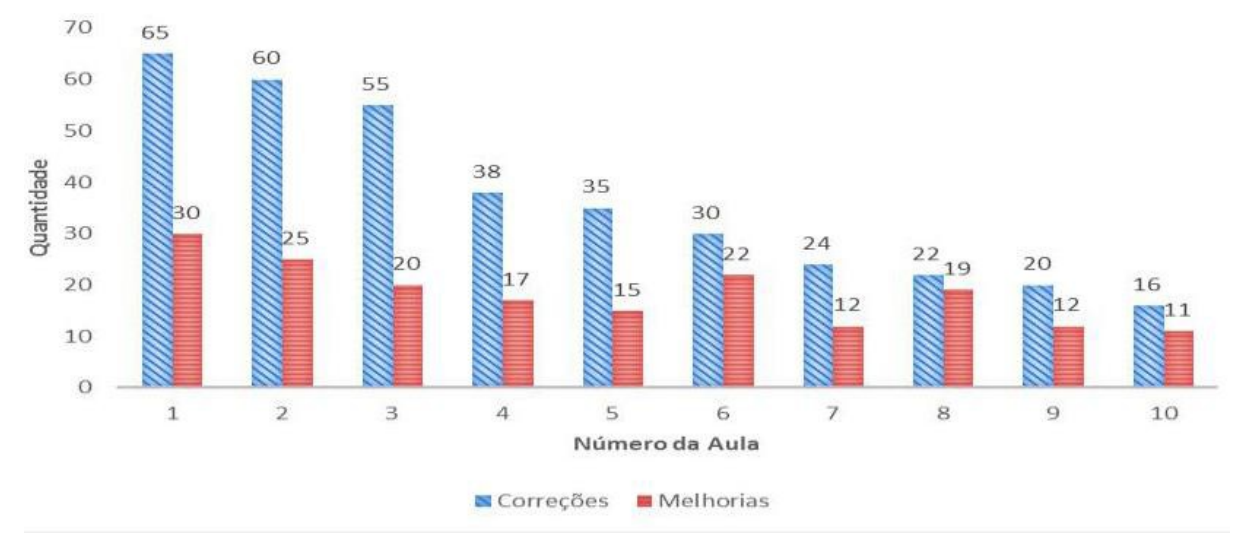

Figura 9 - Correções e Melhorias demandadas pela equipe de testes. 
Observamos que para dez aulas, a equipe de testes detectou trezentos e sessenta e cinco erros e solicitaram cento e oitenta e três melhorias ao OA. Isso quer dizer que a aplicação desta metodologia de testes permitiu identificar, corrigir e melhorar o Visual JO2, impedindo que este chegasse ao público alvo com erros que inviabilizassem seu uso.

Na seção seguinte serão apresentadas as considerações finais.

\section{CONSIDERAÇÕES FINAIS}

Este trabalho apresenta o Visual JO2, um objeto de aprendizagem acessível, que busca facilitar o processo de ensino-aprendizagem de linguagem de programação Java à PCD através do estimulo visual.

Embora a programação orientada ao visual seja uma pesquisa que data da década de setenta, o Visual JO2 inova este quando concretiza um objeto, considerado abstrato. O Visual JO2 é o conteúdo digital preferencialmente adotado pela comunidade de testes, tratados como alunos de um curso piloto. Sessenta e sete por cento do total afirmam que o estimulo visual e apresentação dos conteúdos são os grandes atrativos da ferramenta, validando o forte apelo ao sentido da visão.

Visando a melhoria constante do material disponibilizado, o Le@d aplica uma metodologia de testes sobre o Visual JO2 que prevê duas fases de aplicação, levantamento de erros e melhorias e evolução do conteúdo proposto. As etapas de teste e evolução envolvem uma comunidade PCD semelhante ao aluno final. Essa metodologia de testes permite disponibilização de um conteúdo de qualidade a um público bastante exigente. Por fim, os resultados indicam que noventa e sete do público de testes são atraídos pelo visual ou caráter prático associado ao Visual JO2.

\section{REFERÊNCIAS}

Barbosa, M. R. G., Silva, F. A. Oliveira, V. M. A. Feltrim, V. D., Mirisola, L. G. B. Gonçalves, P. C. Ramos, J. J. G. e Alves, L. T. (2009) "Implementação de Compilador e Ambiente de Programação Icônica para a Linguagem Logo em um Ambiente de Robótica Pedagógica de Baixo Custo”. Anais do XX Simpósio Brasileiro de Informática na Educação.

BLATTO-VAlle, R. R. Kelly, M. G. Gaustad, J. Porter, and J. Fonzi. Visual-spatial representation in mathematical problem solving by deaf and hearing students. Journal of Deaf Studies and Deaf Education,12(4):432-448, 2007.

DANTAS, André. Apresentando o BEM: Um Objeto de Aprendizagem para mediar o processo educacional de crianças com deficiência visual e videntes nas operações básicas de Matemática. II Congresso Brasileiro de Informática na Educação CBIE. 2013.

FARINELLI, Fernanda. Conceitos básicos de programação orientada a Objetos. IFMI. Minas Gerais. 2007.

FURTADO, Corneli. Um modelo para a produção de Objetos de Aprendizagem Acessíveis: Modelagem e Análise por Redes de Petri Coloridas. Dourados- MS. Simpósio Brasileiro de Informática na Educação. 2014.

IBGE (2014). Online: disponível em: <brasil/nosso-povo/caracteristicas-da-populacao>. Acesso em Maio de 2014. 
IEEE LTSC (2010). Ieee learning technology steards committee. Disponível em: <http://ieeeltsc.org. $>$. Acesso em: Dezembro de 2013.

PIOVESAN, Sandra. Sistema Imersivo para Pessoas com Deficiência. Simpósio Brasileiro de Informática na Educação. 2013.

PICCOLO, Homero. Ambiente Interativo e Adaptável para ensino de Programação. Brasília. Departamento de Ciência da Computação - UnB. 2010.

PINTO, M. A. d. S.; GOMES, A. M. d. S, and Y. E. Nicot. A experiência visual como elemento facilitador na educação em ciências para alunos surdos. Revista Aret e: Revista Amazônica de Ensino de Ciências, 5(09), 2014.

SOFFA, Marilice; ALCÂNTARA, Paulo. O uso do Software Educativo: Reflexões da prática docente na sala de aula informatizada. Curitiba-PR. VIII Congresso Nacional de Educação. 2008. 